\title{
Musculoskeletal Injury
}

National Cancer Institute

\section{Source}

National Cancer Institute. Musculoskeletal Injury. NCI Thesaurus. Code C110943.

Damage to the muscles, bones and their supportive structural attachments. 